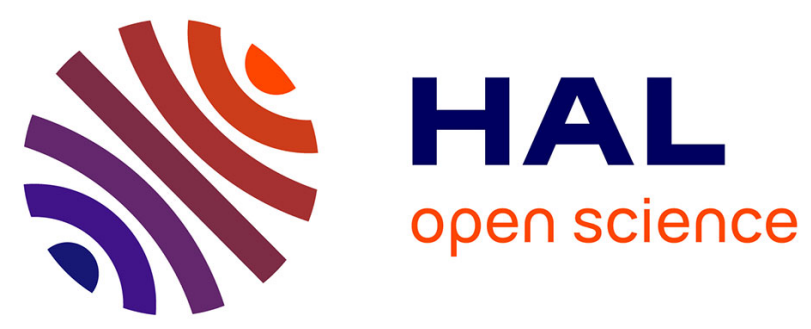

\title{
Ring-opening metathesis polymerization of cyclooctene derivatives with chain transfer agents derived from glycerol carbonate
}

\author{
Abdou K. Diallo, Liana Annunziata, Stéphane Fouquay, Guillaume Michaud, \\ Frédéric Simon, Jean-Michel Brusson, Sophie M. Guillaume, Jean-François \\ Carpentier
}

\section{To cite this version:}

Abdou K. Diallo, Liana Annunziata, Stéphane Fouquay, Guillaume Michaud, Frédéric Simon, et al.. Ring-opening metathesis polymerization of cyclooctene derivatives with chain transfer agents derived from glycerol carbonate. Polymer Chemistry, 2014, 5 (7), pp.2583-2591. 10.1039/C3PY01639K . hal-01058100

\section{HAL Id: hal-01058100 https://hal-univ-rennes1.archives-ouvertes.fr/hal-01058100}

Submitted on 26 Aug 2014

HAL is a multi-disciplinary open access archive for the deposit and dissemination of scientific research documents, whether they are published or not. The documents may come from teaching and research institutions in France or abroad, or from public or private research centers.
L'archive ouverte pluridisciplinaire HAL, est destinée au dépôt et à la diffusion de documents scientifiques de niveau recherche, publiés ou non, émanant des établissements d'enseignement et de recherche français ou étrangers, des laboratoires publics ou privés. 


\section{Ring-Opening Metathesis Polymerization of Cyclooctene Derivatives with Chain Transfer Agents derived from Glycerol Carbonate}

Abdou K. Diallo, ${ }^{a}$ Liana Annunziata, ${ }^{a}$ Stéphane Fouquay, ${ }^{b}$ Guillaume Michaud, ${ }^{\mathrm{c}}$ Frédéric Simon, ${ }^{\mathrm{c}}$ Jean-Michel Brusson, ${ }^{\mathrm{d}}$ Sophie M. Guillaume ${ }^{*, \mathrm{a}}$ and Jean-François Carpentier*,

${ }^{a}$ Institut des Sciences Chimiques de Rennes, Organometallics: Materials and Catalysis Dept., UMR 6226 CNRS-Université de Rennes 1, F-35042 Rennes Cedex (France)

${ }^{\mathrm{b}}$ BOSTIK S.A. 16-32, Rue H. Regnault, F-92902 Paris La Défense (France)

${ }^{\mathrm{c}}$ BOSTIK CRD, Route de Bailly, F-60771 Ribécourt Cedex (France)

${ }^{\mathrm{d}}$ TOTAL Corporate Research, F-92069 Paris La Défense (France)

* To whom correspondence should be addressed. Email: jean-francois.carpentier@univrennes1.fr, $\quad$ sophie.guillaume@univ-rennes1.fr, Phone: +33 (0)223235950, Fax: +33 (0)223236939 


\begin{abstract}
The synthesis of a variety of mono- and di-(glycerol carbonate) telechelic polyolefins has been achieved upon ruthenium-catalyzed ring-opening metathesis polymerization (ROMP) of cyclooctene (COE) derivatives in the presence of a vinyl or acryloyl derivative of glycerol carbonate (GC) acting as a chain-transfer agent (CTA). Reaction monitoring based on SEC and ${ }^{1} \mathrm{H}$ NMR analyses suggested that the ROMP proceeds through the formation of first the $\alpha$-GC, $\omega$-vinyl-poly(cyclooctene) (PCOE) intermediate, which eventually evolves over time into the $\alpha, \omega$-di(GC)-PCOE. The nature of the solvent was shown to have a significant impact on both the reaction rates and the eventual selectivity for the mono-/di-telechelic PCOE. ROMP of 3-alkyl (methyl, ethyl, $n$-hexyl)-substituted COEs (3-R-COEs) afforded only the $\alpha$-GC, $\omega$-vinyl-poly(3-R-COE)s, as the result of the steric hindrance around the active intermediate, while a 5-ethyl substituted COE (5-Et-COE) enabled to access the corresponding $\alpha, \omega$-di(GC)-poly(5-Et-COE). The ROMP of 5,6-epoxy-, 5-hydroxy- and 5-oxo-functionalized COEs in the presence of acryloyl-GC as CTA has also been achieved, affording from the two first monomers polymers with GC end-groups at both extremities, while a 60:40 mixture of mono- and di-GC terminated $\mathrm{P}(5-\mathrm{O}=\mathrm{COE})$ was observed in the latter case.
\end{abstract}




\section{Introduction}

Functionalized telechelic poly(butadiene)s (PBDs) are extensively used in the polyurethane industry as cross-linking agents in the preparation of products ranging from sealants and adhesives to rocket propellant binders. ${ }^{1}$ Such telechelic polymers are often synthesized by radical or anionic polymerization methods which usually require demanding conditions and induce varying amounts of 1,2-linkages in the polymer backbone. ${ }^{2}$ This leads to average number of functional groups per polymer chain $\left(F_{\mathrm{n}}\right)$ values that greatly deviate from 2 , and it also limits the elastomeric potential of the ultimate materials. ${ }^{3}$ Recent advances in rutheniumcatalyzed ring-opening metathesis polymerization (ROMP) have provided new opportunities for the preparation of such telechelic polymers with $F_{n}=c a .2$, when functionalized chaintransfer agents (CTAs) are employed. In comparison to tungsten- and molybdenum-based catalysts, Grubbs' catalysts based on ruthenium complexes are widely used in ROMP thanks to their tolerance toward protic functional groups, oxygen, and moisture. ${ }^{4}$ When symmetric acyclic substituted alkenes are employed as CTAs, only the $\alpha, \omega$-telechelic polymers are produced. Thus, dihydroxy-telechelic poly(butadiene)s (HTPBDs) have been obtained via the Ru-catalyzed ROMP of cyclooctene $(\mathrm{COE}){ }^{5}{ }^{1,5}$-cyclooctadiene $(\mathrm{COD})^{6-8}$ or 1,5-dimethyl1,5-cycloctadiene (DMCOD) ${ }^{9}$ in the presence of cis-1,4-bis(acetoxy)-2-butene as CTA, followed by a post-polymerization deprotection step of the acetoxy groups. Similarly, the synthesis of dicarboxy- and diamino-telechelic PBDs has been reported from cis-1,4-bis(2tert-butoxycarbonyl)-2-butene and cis-1,4-di-tert-butyl-2-butene-1,4-dicarbamate as CTAs, respectively. ${ }^{10}$ Hillmyer and co-workers have described the use of unprotected maleic acid as a CTA in the ROMP of COE mediated by Grubbs' $2^{\text {nd }}$-generation catalyst $(\mathbf{G 2})$, to afford $\alpha, \omega$-dicarboxy-telechelic PCOE. ${ }^{11}$ Also, high molar mass dicyano- and dichloro-telechelic PBDs have been synthesized via G2-catalyzed ROMP of COD in the presence of 1,4dicyano-, 1,8-dicyano-4-octene or 1,4-dichloro-2-butene as difunctional CTAs. ${ }^{12,13}$ On the 
other hand, there are only a few reports on Ru-catalyzed ROMP in the presence of heteroatom-substituted vinyl substrates as CTAs. Grubbs and coworkers prepared endfunctionalized poly(norbornene)s (PNBs) using $\mathrm{Cl}_{2}(\mathrm{PCy})_{2} \mathrm{Ru}=\mathrm{CHPh}$ as the ROMP catalyst and allyl acetate as CTA. ${ }^{14} \alpha$-Acetoxy, $\omega$-vinyl-PNB was thus recovered as the major product along with small amounts of bis-acetoxy and bis-vinyl end-functionalized PNBs. Acryloyl species were used as CTAs for ring-opening cross metathesis (ROCM) of COD or trisubstituted cycloolefins mediated by $\mathbf{G 2}$ catalyst. $^{15}$ With COD as monomer, $\alpha, \omega-$ diacrylate-poly(COD)s (PCODs) were synthesized whereas with the trisubstituted cycloolefins, the acrylate moiety was eventually found only onto the less-substituted chainend.

Valorization of glycerol, a cheap and largely available renewable resource derived from biodiesel production, has become a topical challenge for (agro)chemical industries. Among possible useful green chemicals derived thereof, the inexpensive glycerol carbonate (4-hydroxymethyl-1,3-dioxolan-2-one; hereafter referred to as cyclocarbonate or GC) has been investigated as a non-volatile reactive solvent and novel component for a variety of materials. ${ }^{16-18}$ In a prior study, we have reported the use of GC as a CTA in the "immortal" ring-opening polymerization (ROP) of trimethylene carbonate (TMC) leading to $\alpha$-GC endfunctionalized poly(trimethylene carbonate) (PTMC). ${ }^{19}$ Subsequent transformation of the $\omega$-hydroxy chain-end into a GC moiety eventually afforded $\alpha, \omega$-di(GC) telechelic PTMC. We have shown that this latter polymer can undergo a carbonate ring-opening polyaddition with a diamine to afford poly(hydroxyurethane)s (PHUs), ${ }^{19}$ a class of the so-called NonIsocyanate PolyUrethanes (NIPUs) of high topical interest. ${ }^{20-26}$

Also, taking advantage of the high tolerance of ROMP catalysts toward functional groups, we have recently communicated on the first synthesis of mono- and di-cyclocarbonate 
end-functionalized polyolefins through the ROMP of COE in the presence of vinyl and acryloyl derivatives of GC as CTAs, respectively. ${ }^{27}$ In order to better understand the mechanism of these ROMP reactions in the presence of $\mathbf{G C}$ derivatives, so as to improve the overall efficiency and the scope of the process and to eventually access to room-temperature liquid materials (much more useful for formulation of end-products such as NIPUs), we have now explored in details the ROMP of COE and of a variety of 3- and 5-substituted COE derivatives (Schemes 1, 3, 5). Herein, we describe the selective synthesis and the characterization of the resulting mono- and di-telechelic PCOEs and provide mechanistic insights into the ROMP process, notably by taking into account the substitution pattern of the cycloolefin.

\section{Experimental Section}

Chemicals. All the syntheses and manipulations of air- and moisture-sensitive materials were carried out in Schlenk-type glassware on a dual-manifold Schlenk line. Cyclooctene (COE), $\left[\left(\mathrm{IMesH}_{2}\right)\left(\mathrm{Cy}_{3} \mathrm{P}\right) \mathrm{RuCl}_{2}(=\mathrm{CHPh})\right] \quad$ (Grubbs' $2^{\text {nd }}$-generation catalyst, G2) and 4-vinyl-1,3dioxolan-2-one (1) were purchased from Sigma-Aldrich. COE was first degassed and dried over $\mathrm{CaH}_{2}$ overnight and then distilled before use. All other reagents were used as received. (2-Oxo-1,3-dioxolan-4-yl)methyl acrylate (2), ${ }^{27} 3$ - or 5-alkyl-substituted COEs (3-Me-COE, ${ }^{28}$ 3-Et-COE, ${ }^{28} 3-n$-Hex-COE, ${ }^{28}$ 5-Et-COE $\left.{ }^{29}\right)$ and functionalized COEs (5,6-epoxy-COE, 5-OH$\mathrm{COE}, 5-\mathrm{O}=\mathrm{COE})^{30}$ were synthesized according to the reported literature procedures.

Characterization. NMR spectra were recorded on AM-400 and AM-500 Brüker spectrometers at $298 \mathrm{~K}$ in $\mathrm{CDCl}_{3}$. A relaxation delay of $3 \mathrm{~s}$ was used during the acquisition to afford quantitative ${ }^{1} \mathrm{H}$ and ${ }^{13} \mathrm{C}$ NMR spectra. The chemical shifts are referenced to tetramethylsilane (TMS) and were determined using the residual proton $\left({ }^{1} \mathrm{H}\right)$ and carbon $\left({ }^{13} \mathrm{C}\right)$ 
resonances of the deuterated solvent. Molar mass $\left(M_{\mathrm{n}}\right.$ and $\left.M_{\mathrm{w}}\right)$ and dispersity $\left(\bigoplus_{\mathrm{M}}=M_{\mathrm{w}} / M_{\mathrm{n}}\right)$ values of polymers were determined by Size Exclusion Chromatography (SEC) using a Polymer Laboratories PL-GPC 50 instrument equipped with two ResiPore Mixed E $300 \times 7.5$ mm columns and a refractive index detector. The samples were eluted with $\mathrm{THF}$ at $30{ }^{\circ} \mathrm{C}$ at $1.0 \mathrm{~mL} \cdot \mathrm{min}^{-1}$ and the columns were calibrated using 11 monodisperse polystyrene standards (range of $M_{\mathrm{n}}=580$ to $380,000 \mathrm{~g} \cdot \mathrm{mol}^{-1}$ ). The reported molar mass values are uncorrected for the possible difference in hydrodynamic volumes of the polymers vs. polystyrene.

Molar mass values determined by ${ }^{1} \mathrm{H}$ NMR spectroscopy $\left(M_{\mathrm{n}, \mathrm{NMR}}\right)$ were calculated from the integral value ratio of the signals of end-groups hydrogens to internal olefin hydrogens. The theoretical molar mass of polymers was calculated from the formula: $M_{\mathrm{n}, \text { theo }}$ $=\mathrm{M}($ monomer $) \times[\text { monomer }]_{0} /\left([\mathrm{CTA}]_{0} / F_{\mathrm{n}}\right) \times$ conversion $($ monomer $)$, where $F_{\mathrm{n}}$ is the functionality of the polymer (i.e., the number of GC groups per macromolecular chain; $1 \leq F_{\mathrm{n}}$ $\leq 2)$

Differential scanning calorimetric (DSC) analysis was performed on a Setaram DSC 131 apparatus, calibrated with indium, at a rate of $10^{\circ} \mathrm{C} \mathrm{min}^{-1}$, under continuous flow of helium $\left(25 \mathrm{~mL} \mathrm{~min}^{-1}\right)$, using aluminum capsules. Reported values were obtained from the second run.

FTIR spectra of the polymers were acquired on a Shimadzu IR-Affinity-1 equipped with an ATR (32 scans, resolution $=4 \mathrm{~cm}^{-1}$ ).

General ROMP Procedure. All polymerizations were performed similarly according to the following typical procedure (Table 1 , entry 1 ). The only differences lie in the nature of the CTA and in its initial concentration ([CTA $\left.]_{0}\right)$. Under argon atmosphere, COE $(1.4 \mathrm{~mL}, 10.8$ mmol) and dry THF (5.0 mL) were placed in a $100 \mathrm{~mL}$ flask. Then, under stirring, 4-vinyl1,3-dioxolan-2-one (1) $(50.0 \mu \mathrm{L}, 0.54 \mathrm{mmol})$ was syringed in and the flask was immersed in 
an oil-bath at $40{ }^{\circ} \mathrm{C}$ immediately before adding, via a cannula, a THF (2 mL) solution of $\mathbf{G 2}$ catalyst $(5.0 \mathrm{mg}, 5.0 \mu \mathrm{mol})$. The reaction mixture turned highly viscous within $2 \mathrm{~min}$. The viscosity then slowly decreased over the next $10 \mathrm{~min}$, and after several hours the reaction medium became completely fluid. After the desired reaction time (typically 2 or $24 \mathrm{~h}$ ), the solvent was concentrated under vacuum. The polymer was then recovered upon precipitation in excess methanol $(100 \mathrm{~mL})$ (thereby allowing removal of the catalyst), filtration and drying at $23 \pm 2{ }^{\circ} \mathrm{C}$ under vacuum (94\% yield). All polymers were recovered as colorless materials, readily soluble in chloroform and THF, and insoluble in methanol.

\section{Results and Discussion}

ROMP of COE and 3-R-COEs ( vinyl-GC (1) and acryloyl-GC (2) using Grubbs' $2^{\text {nd }}$-generation catalyst (G2) was first explored in THF at $40{ }^{\circ} \mathrm{C}$ over $24 \mathrm{~h}$ (Table 1, Scheme 1). The high isolated yields (94-98\%) and the absence of monomer in the ${ }^{1} \mathrm{H}$ NMR spectra of the crude reaction products were coherent with quantitative monomer consumption. In all cases, the experimental molar mass of the polymers $\left(M_{\mathrm{n}, \mathrm{NMR}}\right.$ or $\left.M_{\mathrm{n}, \mathrm{SEC}}\right)$ was found to vary inversely proportionally to the amount of CTA (compare entries $1 / 2,3 / 4 \ldots 15 / 16$ ); this evidenced an efficient chain-transfer process. 
Scheme 1. Synthesis of $\alpha, \omega$-di(GC)-PCOEs from the ROMP of COE using $\mathbf{G} 2$ catalyst and $\mathbf{1}$ or 2 as CTA.

All the PCOEs recovered using $\mathbf{1}$ or $\mathbf{2}$ as CTA for the ROMP of unsubstituted COE over 24 h (Table 1, entries 1-4) displayed the same structure featuring $\mathbf{G C}$ end-groups at both termini $\left(F_{n}=2\right)$; this is illustrated in Figure 1 which shows the ${ }^{1} \mathrm{H}$ NMR and ${ }^{13} \mathrm{C}\left\{{ }^{1} \mathrm{H}\right\} \mathrm{NMR}$ spectra of the PCOE prepared from 20 equiv. of $\mathbf{1}$. The signals corresponding to the $\mathbf{G C}$ endgroups are found at $\delta 4.12-5.04 \mathrm{ppm}$, in a 1:1 ratio with the signals for the vinylidene hydrogens (H4, $\delta 5.49$ ppm; H5, $\delta 5.92 \mathrm{ppm}$ ), as expected. In addition, the ${ }^{13} \mathrm{C}\left\{{ }^{1} \mathrm{H}\right\}$ NMR spectrum shows the signals at $\delta 154.8 \mathrm{ppm}$ and $\delta 77.9$ and $69.3 \mathrm{ppm}$ assigned to the carbonyl and the two other carbons of the 5-membered GC moiety, respectively. FT-IR spectroscopy confirmed these results with the presence of the vibration band at $v 1810 \mathrm{~cm}^{-1}$ corresponding to the carbonyl stretching in the GC moiety (ESI, Fig. S1). The telechelic PCOEs prepared from CTA 2 (Table 1, entries 3-4) all displayed the same structure with two GC end-groups, as previously reported (ESI, Fig. S2-S4). ${ }^{27}$ 

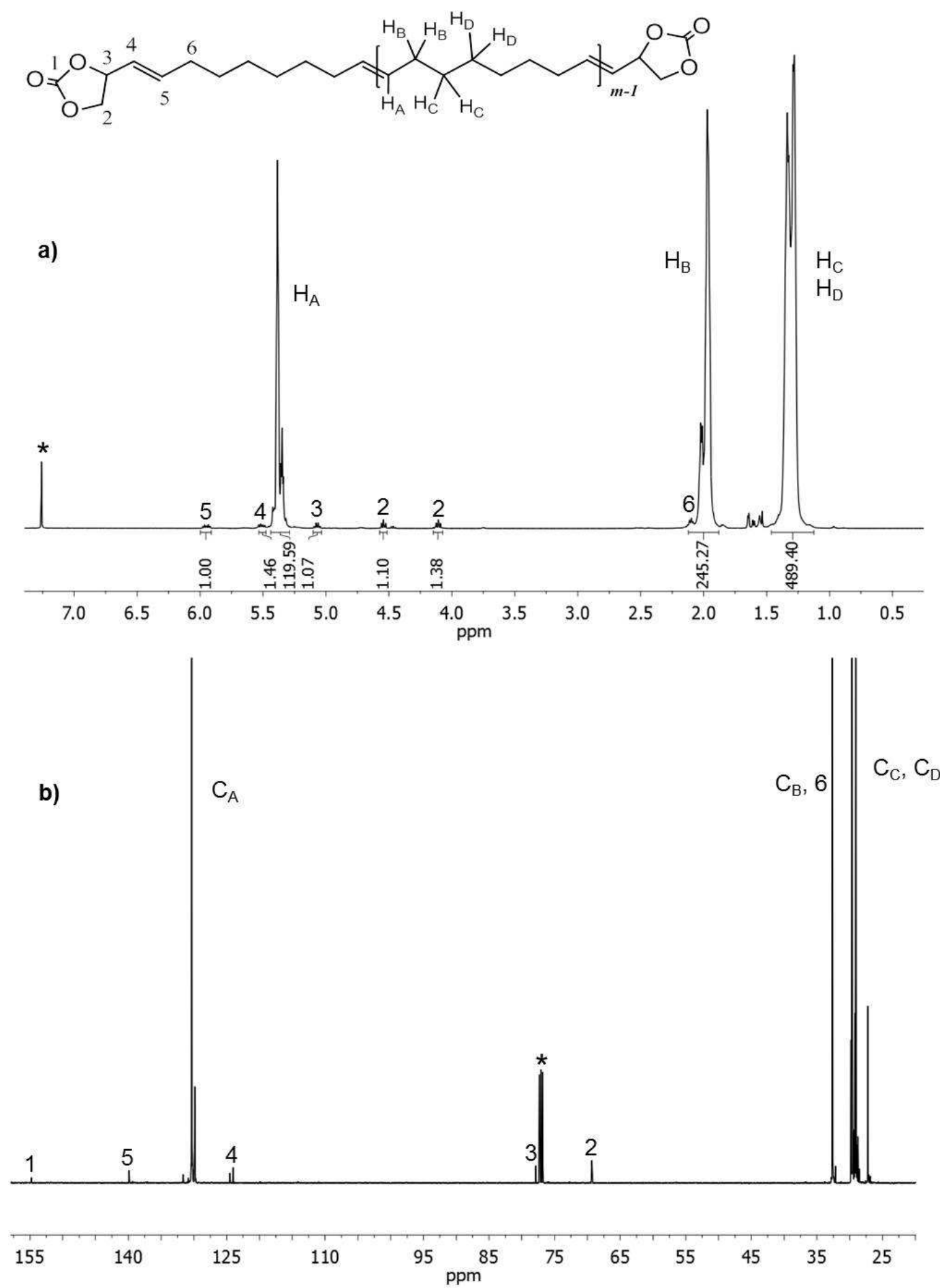

Figure 1. ${ }^{1} \mathrm{H}$ NMR (a, top) and ${ }^{13} \mathrm{C}\left\{{ }^{1} \mathrm{H}\right\}$ (b, bottom) NMR spectra (400 and $100 \mathrm{MHz}, \mathrm{CDCl}_{3}$, $298 \mathrm{~K})$ of an $\alpha, \omega$-di(GC)-PCOE synthesized from the ROMP of COE mediated by G2 catalyst in the presence of $\mathbf{1}$ as CTA (Table 1, entry 1) (* stands for residual solvent resonances). 
The polymer functionality and molar mass value in the ROMP of COE with $\mathbf{1}$ and $\mathbf{2}$ as CTAs were monitored by ${ }^{1} \mathrm{H}$ NMR and SEC over the reaction course, respectively. In both cases, the molar mass of the recovered PCOEs was found to decrease with time, before reaching a plateau (ESI, Fig. S5). This is consistent with the swift increase of the viscosity of the reaction mixture observed at the initial stage of the polymerization, followed by its gradual decrease over longer reaction times. ${ }^{\star}$ When the ROMP of COE was performed in the presence of $\mathbf{1}$ as CTA, a vinyl end-group along with a $\mathbf{G C}$ at the other terminus $\left(F_{n}=1\right)$ was obtained in the polymers recovered from the reaction carried out over $2 \mathrm{~h}$, while after $24 \mathrm{~h}$, PCOEs were then end-capped with one $\mathbf{G C}$ end-group at both chain-ends $\left(F_{n}=2\right)$. This clearly indicated that the nature of end-groups in the final polymer changes as the reaction proceeds. As depicted in Figure 2, a similar time evolution of the selectivity for the monoand di-functionalized PCOEs was observed in the presence of $\mathbf{2}$ as CTA, but over a significantly shorter time period. After 10 min of reaction, $100 \%$ of $\alpha$-vinyl, $\omega$-GC-PCOE were formed; then, the amount of this latter product decreased concomitantly with the increase of the amount of $\alpha, \omega-\operatorname{di}(\mathbf{G C})-\mathrm{PCOE}$ up to $100 \%$ selectivity throughout a period of 2 h. In comparison with vinyl-GC (1), this clearly showed that the electron-poor acrylate-GC (2) is a more active CTA. The functionality of PCOEs is therefore highly dependent on both the reaction time and nature of the CTA.

\footnotetext{
$\$$ Upon adding the $\mathbf{G} 2$ catalyst to the reagents, the reaction mixture turned very viscous within 2 min (presumably indicative of the formation of high molar mass PCOE) and then gradually fluidized over time (as a result of cross-metathesis of PCOE with CTA; ESI, Fig. S5).
} 


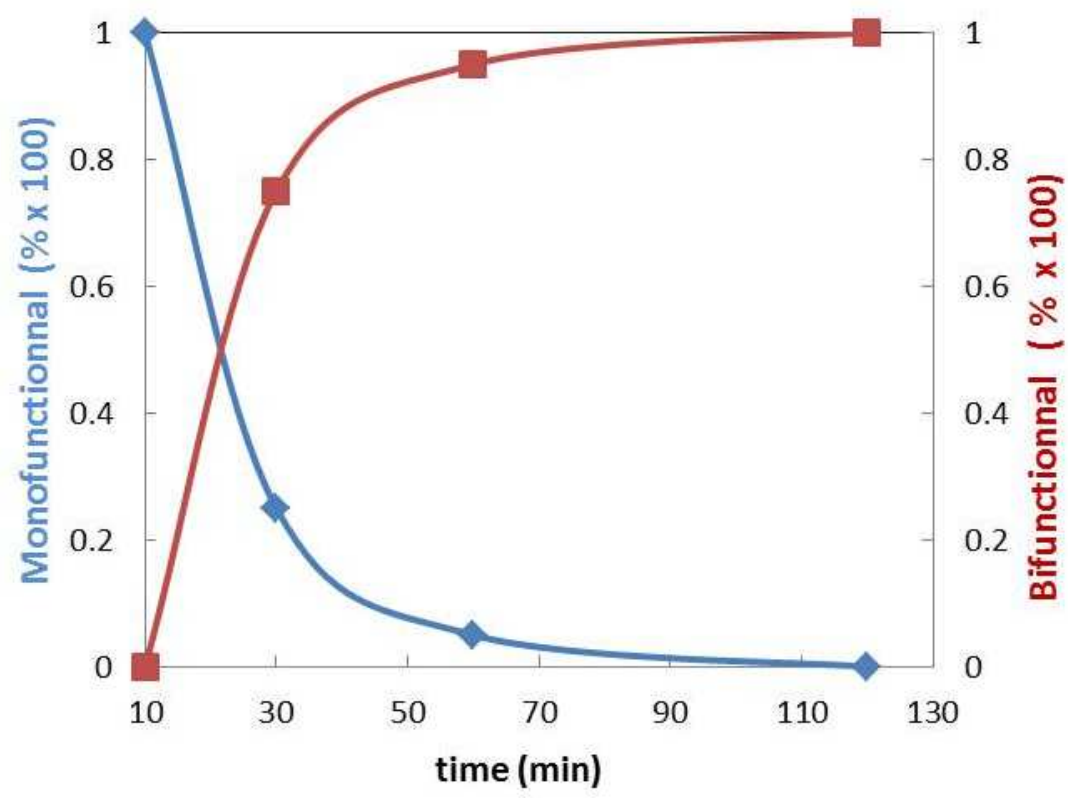

Figure 2. ${ }^{1} \mathrm{H}$ NMR monitoring of the formation of $\alpha$-vinyl, $\omega$-GC-PCOE (monofunctional, and $\alpha, \omega-\operatorname{di}(\mathbf{G C})-\mathrm{PCOE}$ (bifunctional, $\mathbf{-})$ during the ROMP of COE promoted by $\mathbf{G} 2$ catalyst in the presence of $\mathbf{2}$ as CTA (Table 1, entry 3).

THF and dichloromethane (DCM) -two common solvents for metathesis- were selected to evaluate the solvent influence on the ROMP of COE in the presence of $\mathbf{2}$ as CTA. Monitoring of the reaction by ${ }^{1} \mathrm{H}$ NMR showed that, in DCM, at a 2000 (COE):100 (2):1 (G2) ratio, a 40:60 mixture of $\alpha$-vinyl,- $\omega$-GC- and $\alpha, \omega$-di(GC)-PCOEs formed after $24 \mathrm{~h}$ (ESI, Fig. S6). However, in THF, selective formation of the $\alpha, \omega$-di(GC)-PCOE was observed after only $2 \mathrm{~h}$ of reaction (Fig. 2). Hence, a change of the solvent also had a significant impact on the polymer functionality. In fact, this result clearly indicated that the rate of the crossmetathesis reaction between PCOE and CTA 2 was higher in THF as compared to DCM. This trend is in line with literature data on ROMP and cross-metathesis. ${ }^{31}$ Such an acceleration of the rate of ROMP has been accounted for by the increased stability of the four- 
coordinate ruthenium intermediate and/or the assistance of the solvent in the displacement of coordinated $\mathrm{PCy}_{3}$ ligand from the metal center to generate the catalytically active species. ${ }^{32}$

Scheme 2 depicts the proposed mechanistic scenario leading to the formation of endfunctionalized PCOEs from the ROMP of COE in the presence of functionalized olefins 1 or 2 as CTA. After the initial, fast ROMP of COE (leading to high molar mass PCOEs and hence to a highly viscous reaction medium, vide supra), the Ru-alkylidene-polymer terminated with a vinyl group undergoes a cross-metathesis with the CTA to provide a lower molar mass end-differentiated (i.e., vinyl/GC) product; this polymer can further react over the reaction course with another CTA to form the symmetrically GC end-capped products. Besides the gradual decrease in viscosity of the reaction medium observed over time, the ethylene released during such cross-metathesis events was unambiguously evidenced by a GC-MS analysis (ESI, Fig. S7); this further supports this proposed mechanism. 


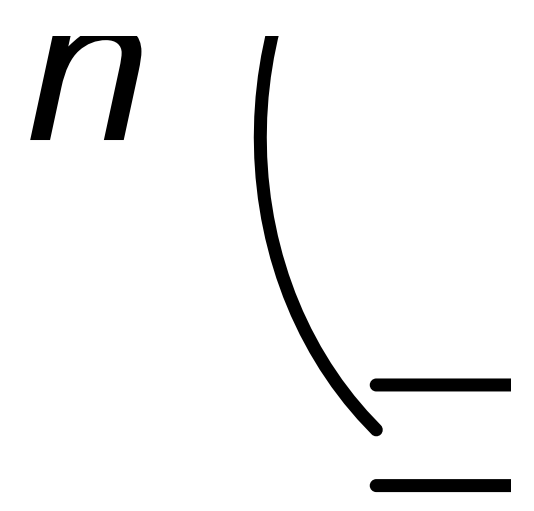

Scheme 2. Simplified mechanisms for the formation of end-differentiated and symmetrically end-capped products via Ring-Opening Metathesis Polymerization (ROMP)/Cross-Metathesis (CM) of COE mediated by $\mathbf{G} 2$ catalyst in the presence of a CTA.

A more efficient route to selective ROMP involving the selective generation of $\alpha$-vinyl, $\omega$-GC-polycycloolefins is using 3-alkyl-substituted COEs (3-R-COEs, Scheme 3, Table 1, entries 5-16). In all cases with $\mathrm{R}=$ methyl, ethyl, hexyl, the recovered $\mathrm{P}(3-\mathrm{R}-\mathrm{COE}) \mathrm{s}$ displayed a single structure with two different chain-end groups: a GC moiety at one terminus and a vinyl on the other extremity. As illustrative example, Figure 3 shows the ${ }^{1} \mathrm{H}$ NMR and ${ }^{13} \mathrm{C}\left\{{ }^{1} \mathrm{H}\right\}$ NMR spectra of the P(3-Et-COE) prepared from 20 equiv of CTA 2 . The signals 
corresponding to the hydrogens of the vinyl chain-end group are observed at $\delta 4.93$ and 5.50 ppm -in a 1:1 ratio with (i) the signals for the internal olefinic hydrogens $\mathrm{H} 14$ and $\mathrm{H} 15$ at $\delta$ 7.04 and $5.86 \mathrm{ppm}$, and (ii) the methylene and methine GC hydrogens at $\delta 4.30$ and $4.94 \mathrm{ppm}$, respectively- and the carbon resonances at $\delta 114.1\left(\mathrm{CH}_{2}=\right)$ and $143.1(=\mathrm{CH}-)$ ppm. Further 2D NMR (COSY, DEPT 135) experiments and FT-IR spectroscopic analyses supported these structures (ESI, Fig. S16-S18). The NMR characterizations of all the mono-functionalized P(3-R-COE)s (see ESI, Fig. S8-S14, S19-S20, S22-S23) clearly evidenced that the 3-alkyl substituted COE monomers opened regioselectively, placing the GC group on the less crowded terminus. Scheme 4 shows a likely pathway accounting for this regioselective ROMP, which involves steric repulsions between the alkyl substituent at the 3-position of COE derivatives (and in the propagating chain) and the ligands on the ruthenium center. ${ }^{33}$ Note that similar results have been reported by Grubbs et al. for the ROCM of 2-Me-COE with various acryloyl specie; ${ }^{15}$ the acrylate was shown to be crossed onto the less-bulky terminus.

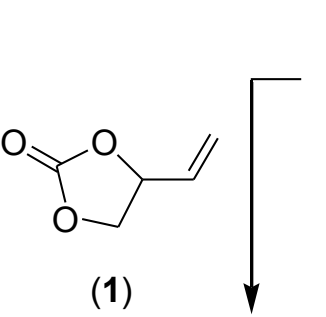<smiles>[R]OC(=O)CC(C)CCCCCC(C)CC1COC(=O)O1</smiles>

$\mathrm{R}=\mathrm{Me}, \mathrm{Et}, n-\mathrm{Hexyl}$

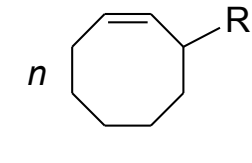

[Ru] (G2) THF, $40{ }^{\circ} \mathrm{C}, 24 \mathrm{~h}$

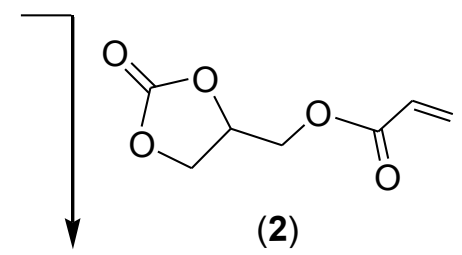

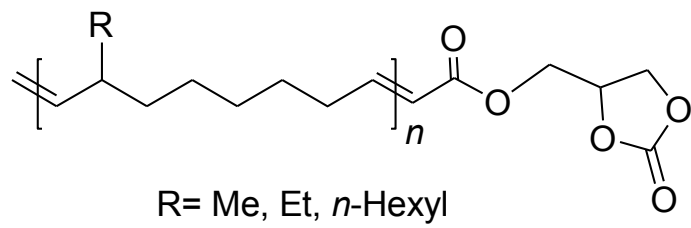

Scheme 3. Synthesis of $\alpha$-vinyl, $\omega$-GC-P(3-R-COE)s from the ROMP of 3-alkyl-substituted COEs using Grubbs' $2^{\text {nd }}$-generation catalyst $(\mathbf{G 2})$ and $\mathbf{1}$ or $\mathbf{2}$ as CTA. 


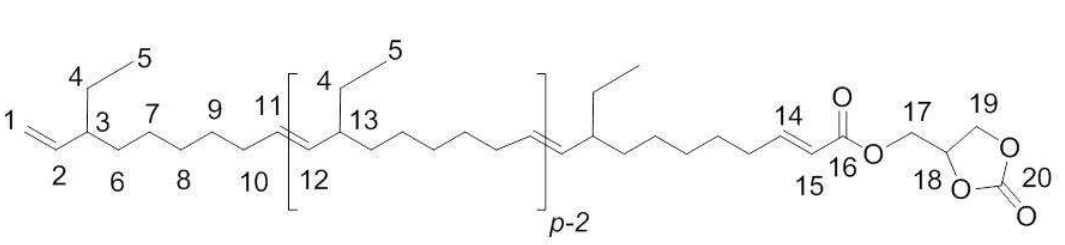

a)

$6-9,4$

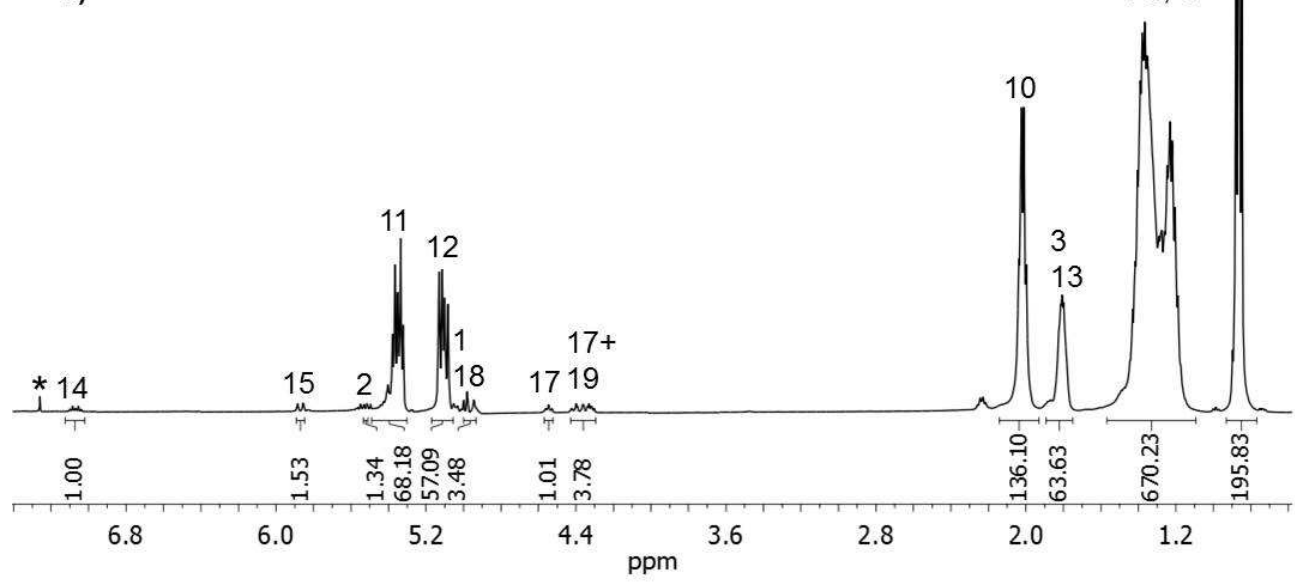

b)

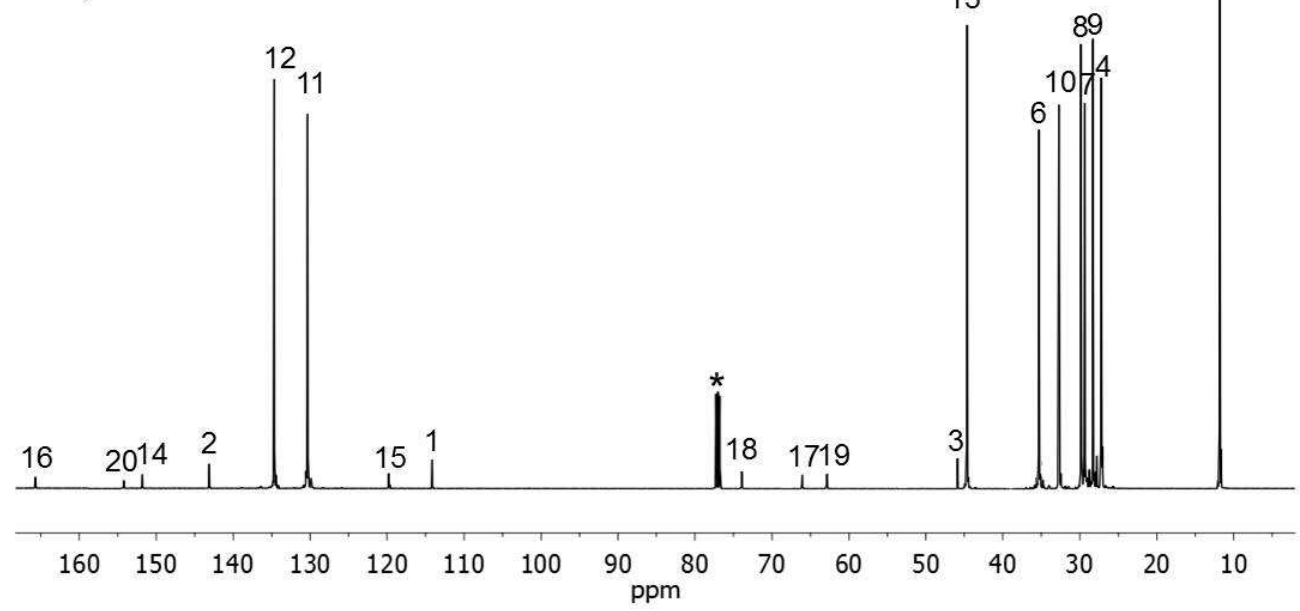

Figure 3. ${ }^{1} \mathrm{H}$ NMR (a, top) and ${ }^{13} \mathrm{C}\left\{{ }^{1} \mathrm{H}\right\} \mathrm{NMR}$ (b, bottom) spectra (400 and $100 \mathrm{MHz}, \mathrm{CDCl}_{3}$, $298 \mathrm{~K}$ ) of an $\alpha$-vinyl, $\omega$-GC-P(3-Et-COE) synthesized from the ROMP of 3-Et-COE in the presence of $\mathbf{2}$ as CTA (Table 1, entry 9) (* stands for residual solvent resonances). 

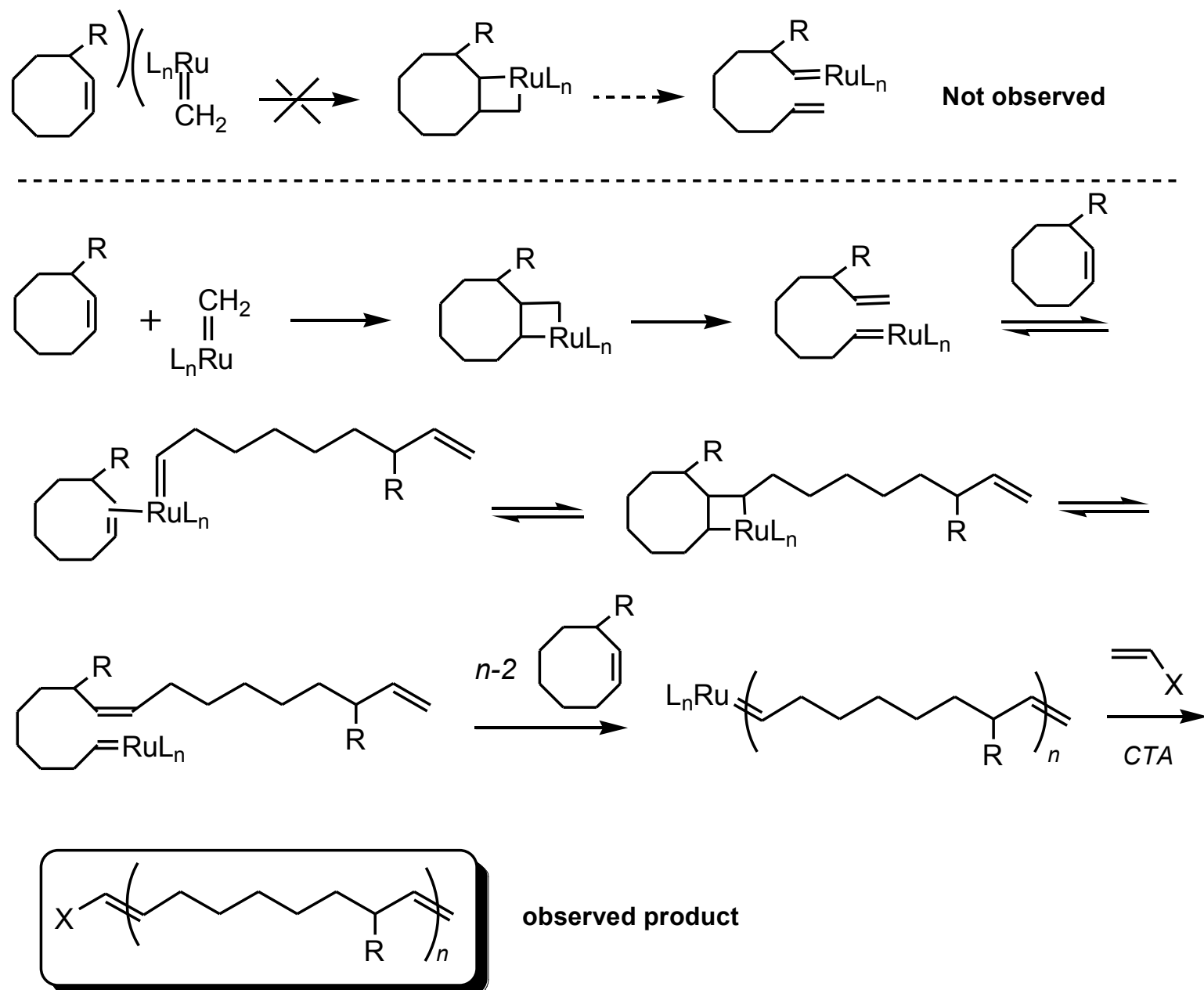

observed product

Scheme 4. Proposed selectivity model for the ROMP of 3-alkyl-substituted COEs mediated by Grubbs' $2^{\text {nd }}$-generation catalyst.

The thermal profiles of these $\alpha$-vinyl, $\omega$-GC-P(3-R-COE) polymers, as determined by Differential Scanning Calorimetry (DSC) analysis, did not exhibit crystallization or melting transitions (in contrast to the corresponding $\alpha$-vinyl, $\omega$-GC-PCOEs; Table 2, entry 1 ),${ }^{27}$ but only a glass transition (Table 2, entries 2-4; ESI, Fig. S10, S15, and S21). As anticipated, the alkyl group in the polymer backbone has a noticeable influence on the thermal behavior: the larger the alkyl chain, the lower the $T_{\mathrm{g}}$. These $T_{\mathrm{g}}$ values are consistent with those previously reported by Wagener and co-workers for polyethylene-type polymers wherein a methyl, ${ }^{34,35}$ 
ethyl $^{35}$ or $n$-hexyl ${ }^{35,36}$ was placed on the ninth backbone carbon (via acyclic diene metathesis (ADMET) of the 6-alkyl-substituted 1,10-undecadiene).

Seeking to get $\alpha, \omega-\operatorname{di}(\mathbf{G C})$ polymers which are liquids at room-temperature (for easier implementation in formulations towards Non-Isocyanate PolyUrethanes, NIPUs), ${ }^{19-26}$ the ROMP of a differently substituted COE derivative, namely 5-Et-COE, was carried out in the presence of $\mathbf{2}$, in a similar approach as that described above for other COEs (Scheme 5; Table 1, entry 17). The recovered material was indeed a liquid $\left(T_{\mathrm{g}}=-65^{\circ} \mathrm{C}\right)$ and functionalized at both termini. Figure 4 shows the ${ }^{1} \mathrm{H}$ and ${ }^{13} \mathrm{C}\left\{{ }^{1} \mathrm{H}\right\}$ NMR spectra of such telechelic $\alpha, \omega$-di(GC)-P(5-Et-COE). The ${ }^{1} \mathrm{H}$ signals of the GC moieties are observed at $\delta 4.32-4.94$ ppm, in a 1:1 ratio with the signals for the internal olefinic hydrogens $\mathrm{H} 7$ and $\mathrm{H} 6$ at $\delta 7.04$ and 5.84 ppm, respectively (Fig. 4a). Correspondingly, the ${ }^{13} \mathrm{C}\left\{{ }^{1} \mathrm{H}\right\}$ NMR spectrum exhibits no signal corresponding to a potential vinylic chain-end group (expected at $\delta 114.1$ and 143.1 ppm; Fig. 3b).

Scheme 5. Synthesis of $\alpha, \omega$-di(GC)-P(5-Et-COE) from the ROMP of COE using Grubbs' $2^{\text {nd }}$-generation catalyst $(\mathbf{G} 2)$ and $\mathbf{2}$ as CTA. 


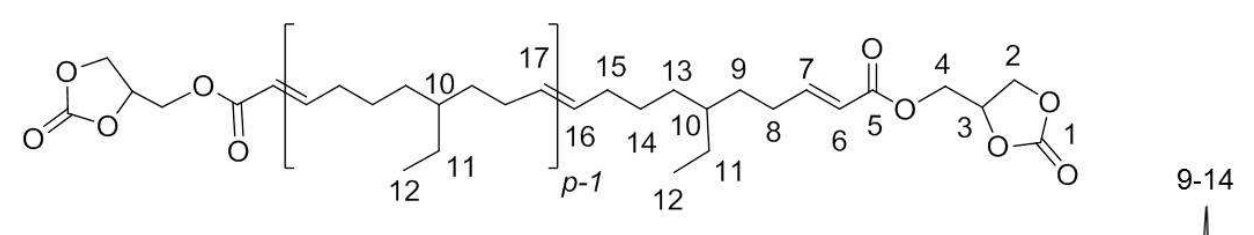

a)

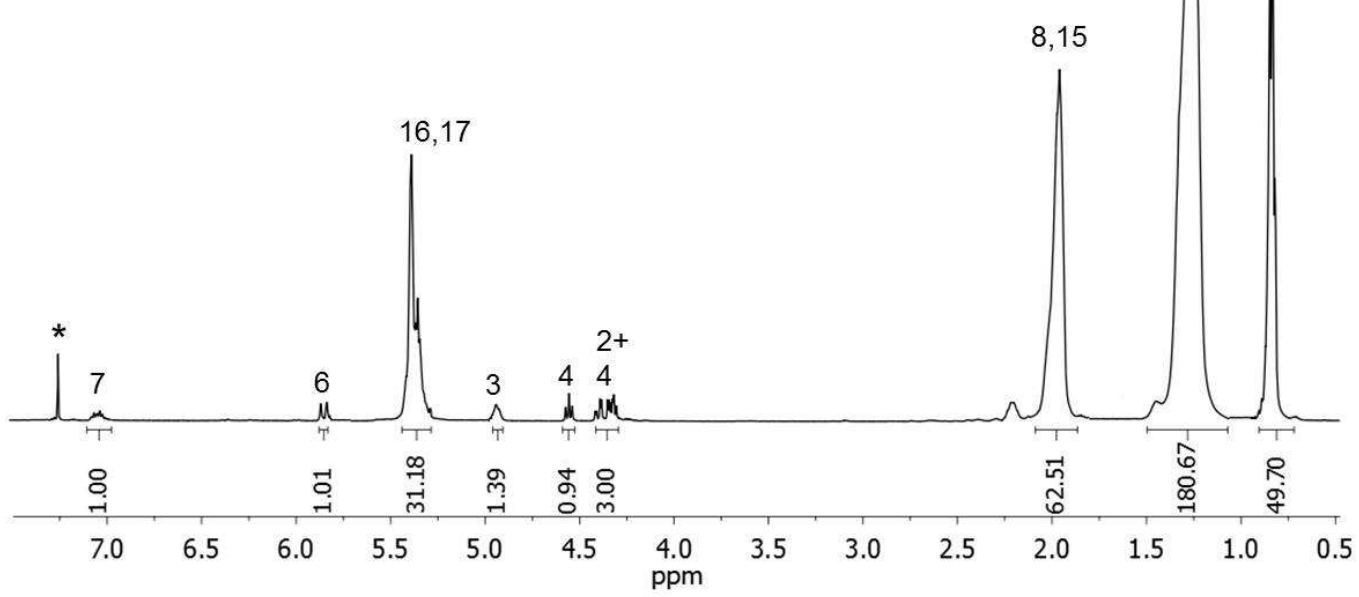

b)

Figure 4. ${ }^{1} \mathrm{H}$ NMR (top) and ${ }^{13} \mathrm{C}\left\{{ }^{1} \mathrm{H}\right\}$ NMR (bottom) spectra (400 MHz and $100 \mathrm{MHz}$, $\left.\mathrm{CDCl}_{3}, 298 \mathrm{~K}\right)$ of an $\alpha, \omega$-di(GC)-P(5-Et-COE) synthesized from the ROMP of 5-Et-COE in the presence of 2 as CTA (Table 1, entry 17; * stands for residual solvent resonances). 
The ROMP of COE derivatives substituted with polar functional groups (5,6-epoxy, 5$\mathrm{OH}$ and $5-\mathrm{O}=$ ) in the presence of the more reactive CTA 2 were also effectively achieved (Table 1, entries 18-20). The polymers were isolated in good yields (typically 94-98\%) and their structures were determined by ${ }^{1} \mathrm{H}$ and ${ }^{13} \mathrm{C}\left\{{ }^{1} \mathrm{H}\right\}$ NMR spectroscopy (see ESI, Fig. S24-25, S27-29). The polymers recovered from the ROMP of 5-OH-COE and 5,6-epoxyCOE after $24 \mathrm{~h}$ reaction exhibited two GC end-groups, one at each terminus $\left(F_{\mathrm{n}}=2\right)$. With the ketone-functionalized COE, a 60:40 mixture of mono- and di-GC terminated P(5$\mathrm{O}=\mathrm{COE}$ ) was typically observed. Attempts to access selectively the telechelic $\alpha, \omega$-di(GC)$\mathrm{P}(5-\mathrm{O}=\mathrm{COE})$ by using longer reaction times or higher catalyst loadings failed. We assume that the ketone group in 5-O=COE was probably responsible for a faster catalyst deactivation, eventually preventing the full cross-metathesis of vinyl chain-ends.

The functional telechelic $\alpha, \omega-\operatorname{di}(\mathbf{G C})-\mathrm{P}(5-\mathrm{OH}-\mathrm{COE})$ and $\alpha, \omega-\operatorname{di}(\mathbf{G C})-\mathrm{P}(5-\mathrm{O}=\mathrm{COE})$ are solid materials at room temperature, while the $\alpha, \omega$-di(GC)-P(5,6-epoxy-COE) is a liquid $\left(T_{\mathrm{g}}=-48^{\circ} \mathrm{C}\right.$, ESI Fig. S26).

\section{Conclusion}

The ROMP of COE derivatives in the presence of acryloyl and vinyl derivatives of GC provides an efficient entry towards a variety of mono- and di-cyclocarbonate polyolefin materials. The selectivity for mono- vs. di-functionalized telechelic polymers is highly dependent on the nature of the solvent, the reaction time, the CTA, and the cycloolefin substrate. Noteworthy, the selectivity of the ROMP of substituted COEs reported here is largely influenced by the substituent position on the cycloolefin. All these observations have been rationalized by a simple mechanistic scenario involving at the initial stage of the reaction the formation of monofunctionalized polymers ultimately converted into the analogous 
difunctionalized ones. The molecular and structural features of the recovered polymers were confirmed by NMR, FTIR and SEC analyses, and their thermal properties were investigated by DSC. Interestingly, polymers having a 3- or 5- alkyl substituent on their backbone, no matter the nature of their end-groups (i.e., mono- or di-GC-functionalized) and their molar mass, feature a low glass transition temperature and are liquid materials at room temperature. This makes them promising precursors towards NIPUs, via eventual reaction with various polyamines. ${ }^{19-26}$ Experiments in these directions are presently in progress in our laboratories and the results will be reported in due course.

\section{Acknowledgments}

This work was financially supported by Bostik and Total Cies (postdoctoral grants to A.K.D. and L.A.).

\section{Electronic Supplementary Information}

Detailed characterization data of polymers.

\section{References}

1. Brosse, J. C.; Derouet, D.; Epaillard, F.; Soutif, J. C.; Legeay, G.; Dušek, K., in Adv. Polym. Sci. 1986, 167-223.

2. Bielawski, C. W.; Scherman, O. A.; Grubbs, R. H. Polymer 2001, 42, 4939-4945.

3. Odian, G. Principles of polymerizations. 3rd ed. New York: Wiley 1991.

4. Trnka, T. M.; Grubbs, R. H. Acc. Chem. Res. 2000, 34, 18-29.

5. Pitet, L. M.; Amendt, M. A.; Hillmyer, M. A. J. Am. Chem. Soc. 2010, 132, 82308231.

6. Bielawski, C. W.; Scherman, O. A.; Grubbs, R. H. Polymer 2001, 42, 4939-4945. 
7. Hillmyer, M. A.; Nguyen, S. T.; Grubbs, R. H. Macromolecules 1997, 30, 718-721.

8. Schwab, P.; Grubbs, R. H.; Ziller, J. W. J. Am. Chem. Soc. 1996, 118, 100-110.

9. Thomas, R. M.; Grubbs, R. H. Macromolecules 2010, 43, 3705-3709.

10. Morita, T.; Maughon, B. R.; Bielawski, C. W.; Grubbs, R. H. Macromolecules 2000, $33,6621-6623$.

11. Pitet, L. M.; Hillmyer, M. A. Macromolecules 2011, 44, 2378-2381.

12. Ji, S.; Hoye, T. R.; Macosko, C. W. Macromolecules 2004, 37, 5485-5489.

13. Ji, S.; Hoye, T. R.; Macosko, C. W. Polymer 2008, 49, 5307-5313.

14. Bielawski, C. W.; Benitez, D.; Morita, T.; Grubbs, R. H. Macromolecules 2001, 34, 8610-8618.

15. Morgan, J. P.; Morrill, C.; Grubbs, R. H. Org. Lett. 2001, 4, 67-70.

16. Behr, A.; Eilting, J.; Irawadi, K.; Leschinski, J.; Lindner, F. Green Chem. 2008, 10, 13-30.

17. Ochoa-Gómez, J. R.; Gómez-Jiménez-Aberasturi, O.; Ramirez-López, C.; Belsué, M. Org. Process Res. Dev. 2012, 16, 389-399.

18. Zhou, C.-H.; Beltramini, J. N.; Fan, Y.-X.; Lu, G. Q. Chem. Soc. Rev. 2008, 37, 527549.

19. Helou, M.; Carpentier, J.-F.; Guillaume, S. M. Green Chem. 2011, 13, 266-271.

20. Sardon, H.; Engler, A. C.; Chan, J. M. W.; Coady, D. J.; O'Brien, J. M.; Mecerreyes, D.; Yang, Y. Y.; Hedrick, J. L. Green Chem. 2013, 15, 1121-1126.

21. Mommer, S.; Lamberts, K.; Keul, H.; Moller, M. Chem. Commun. 2013, 49, 32883290.

22. Alsarraf, J.; Ammar, Y. A.; Robert, F.; Cloutet, E.; Cramail, H.; Landais, Y. Macromolecules 2012, 45, 2249-2256.

23. He, Y.; Keul, H.; Möller, M. React. Funct. Polym. 2011, 71, 175-186. 
24. Anders, T.; Keul, H.; Möller, M. Des. Monomers Polym. 2011, 14, 593-608.

25. Prompers, G.; Keul, H.; Hocker, H. Green Chem. 2006, 8, 467-478.

26. Engels, H.-W.; Pirkl, H.-G.; Albers, R.; Albach, R. W.; Krause, J.; Hoffmann, A.; Casselmann, H.; Dormish, J. Angew. Chem., Int. Ed. 2013, 52, 9422-9441.

27. Annunziata, L.; Fouquay, S.; Michaud, G.; Simon, F.; Guillaume, S. M.; Carpentier, J.-F. Polym. Chem. 2013, 4, 1313-1316.

28. Kobayashi, S.; Pitet, L. M.; Hillmyer, M. A. J. Am. Chem. Soc. 2011, 133, 5794-5797.

29. Kobayashi, S.; Macosko, C. W.; Hillmyer, M. A. Aust. J. Chem. 2010, 63, 1201-1209.

30. Hillmyer, M. A.; Laredo, W. R.; Grubbs, R. H. Macromolecules 1995, 28, 6311-6316.

31. Slugovc, C. Macromol. Rapid Commun. 2004, 25, 1283-1297.

32. Sanford, M. S.; Love, J. A.; Grubbs, R. H. J. Am. Chem. Soc. 2001, 123, 6543-6554.

33. Wu, Z.; Grubbs, R. H. Macromolecules 1995, 28, 3502-3508.

34. Smith, J. A.; Brzezinska, K. R.; Valenti, D. J.; Wagener, K. B. Macromolecules 2000, $33,3781-3794$.

35. Rojas, G.; Berda, E. B.; Wagener, K. B. Polymer 2008, 49, 2985-2995.

36. Sworen, J. C.; Wagener, K. B. Macromolecules 2007, 40, 4414-4423. 
Table 1. ROMP of COE and substituted COE derivatives mediated by Grubbs' $2^{\text {nd }}$-generation catalyst in the presence of $\mathbf{1}$ and $\mathbf{2}$ as CTA over 24 h.

\begin{tabular}{|c|c|c|c|c|c|c|c|c|}
\hline Entry & $\mathrm{R}$ & CTA & $\begin{array}{c}{[\mathrm{R}-\mathrm{COE}]_{0} /} \\
{[\mathrm{CTA}]_{0} /[\mathbf{G} 2]_{0}}\end{array}$ & $F_{\mathrm{n}}{ }^{\mathrm{a}}$ & $\begin{array}{c}M_{\mathrm{n}, \text { theo }}{ }^{\mathrm{b}} \\
\left(\mathrm{g} \cdot \mathrm{mol}^{-1}\right)\end{array}$ & $\begin{array}{c}M_{\mathrm{n}, \mathrm{NMR}}^{\mathrm{c}} \\
\left(\mathrm{g} \cdot \mathrm{mol}^{-1}\right)\end{array}$ & $\begin{array}{c}M_{\mathrm{n}, \mathrm{SEC}}^{\mathrm{d}} \\
\left(\mathrm{g} \cdot \mathrm{mol}^{-1}\right) \\
\end{array}$ & $\bigoplus_{M}{ }^{\mathrm{d}}$ \\
\hline 1 & $\mathrm{H}$ & 1 & 2000:100:1 & 2 & 4400 & 13400 & 9000 & 1.75 \\
\hline 2 & - & 1 & 2000:30:1 & 2 & 14600 & $n d$ & 17400 & 1.43 \\
\hline 3 & - & 2 & 2000:100:1 & 2 & 4400 & 10200 & 6600 & 1.56 \\
\hline 4 & - & 2 & 2000:30:1 & 2 & 14600 & 30200 & 19200 & 1.63 \\
\hline 5 & $3-\mathrm{Me}$ & 1 & 2000:100:1 & 1 & 2500 & 5100 & 7000 & 1.42 \\
\hline 6 & - & 1 & 2000:30:1 & 1 & 8200 & 15200 & 17800 & 1.42 \\
\hline 7 & - & 2 & 2000:100:1 & 1 & 2500 & 4800 & 6200 & 1.46 \\
\hline 8 & - & 2 & 2000:30:1 & 1 & 8200 & 15000 & 19000 & 1.57 \\
\hline 9 & 3 -Et & 1 & 2000:100:1 & 1 & 2800 & 9800 & 6500 & 1.39 \\
\hline 10 & - & $\mathbf{1}$ & 2000:30:1 & 1 & 9100 & 29300 & 19700 & 1.52 \\
\hline 11 & - & 2 & 2000:100:1 & 1 & 2800 & 8000 & 9700 & 1.50 \\
\hline 12 & - & 2 & 2000:30:1 & 1 & 9100 & $n d$ & 17700 & 1.50 \\
\hline 13 & 3-n-Hexyl & 1 & 2000:100:1 & 1 & 3900 & 4900 & 7300 & 1.30 \\
\hline 14 & - & 1 & 2000:30:1 & 1 & 13100 & 14600 & 20600 & 1.38 \\
\hline 15 & - & 2 & 2000:100:1 & 1 & 3900 & 9900 & 9700 & 1.42 \\
\hline 16 & - & 2 & 2000:30:1 & 1 & 13100 & $n d$ & 23600 & 1.41 \\
\hline 17 & $5-\mathrm{Et}$ & 2 & 2000:100:1 & 2 & 5600 & 4600 & 3500 & 1.75 \\
\hline 18 & 5,6-ероху & 2 & 2000:100:1 & 2 & 5000 & 13600 & 6200 & 150 \\
\hline 19 & $5-\mathrm{OH}$ & 2 & 2000:100:1 & 2 & 5100 & 14300 & 15500 & 1.52 \\
\hline 20 & $5-\mathrm{O}=$ & 2 & 2000:100:1 & $<2$ & $<5000$ & $n d$ & 6000 & 1.87 \\
\hline
\end{tabular}

${ }^{a}$ Number of GC group per macromolecular chain. ${ }^{b}$ Theoretical $M_{\mathrm{n}}$ value calculated for complete chain-transfer, from the relation: $M_{\mathrm{n}, \text { theo }}=$ $\mathrm{M}($ monomer $) \times[\text { monomer }]_{0} /\left([\mathrm{CTA}]_{0} / F_{\mathrm{n}}\right) \times$ conversion $($ monomer $)(=100 \%$ for all these experiments $) .{ }^{c}$ Experimental $M_{\mathrm{n}}$ value determined by ${ }^{1} \mathrm{H} \mathrm{NMR}$ (refer to the Experimental Section). ${ }^{\mathrm{d}}$ Experimental $M_{\mathrm{n}}$ and dispersity values determined by SEC (refer to the Experimental Section). 
Table 2. Thermal properties of $\alpha$-vinyl, $\omega$-GC-P(3-R-COE)s obtained by Grubbs' $2^{\text {nd }}-$ generation-catalyzed ROMP of 3-R-COEs in the presence of $\mathbf{1}$ as CTA, as determined by $\operatorname{DSC}\left(10{ }^{\circ} \mathrm{C} \cdot \mathrm{min}^{-1}\right.$, second heating cycle).

\begin{tabular}{ccc}
\hline $\mathrm{R}$ & $T_{\mathrm{g}}\left({ }^{\circ} \mathrm{C}\right)$ & $T_{\mathrm{m}}\left({ }^{\circ} \mathrm{C}\right)$ \\
\hline $\mathrm{H}$ & not observed & 60 \\
$\mathrm{Me}$ & -64 & - \\
$\mathrm{Et}$ & -69 & - \\
$n$-Hexyl & -77 & - \\
\hline
\end{tabular}


For the Table of Content entry

Mono- and di-(glycerol carbonate) telechelic polyolefins have been prepared by ROMP of cyclooctene derivatives in the presence of a chain-transfer agent 